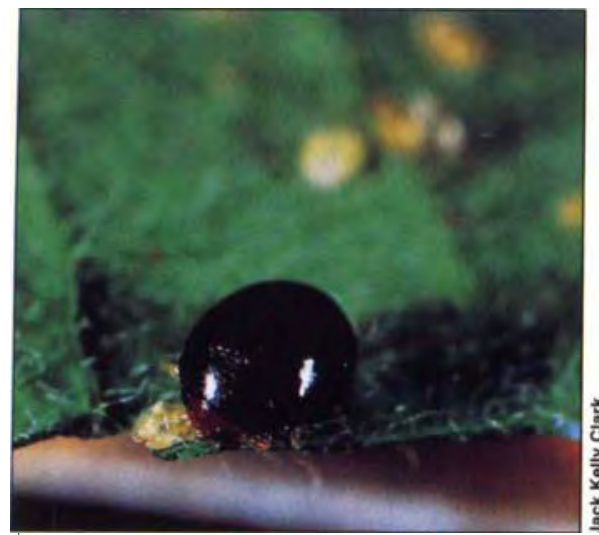

Adult Delphastus pus/llus feeding on a Bemisia tabaci nymph.

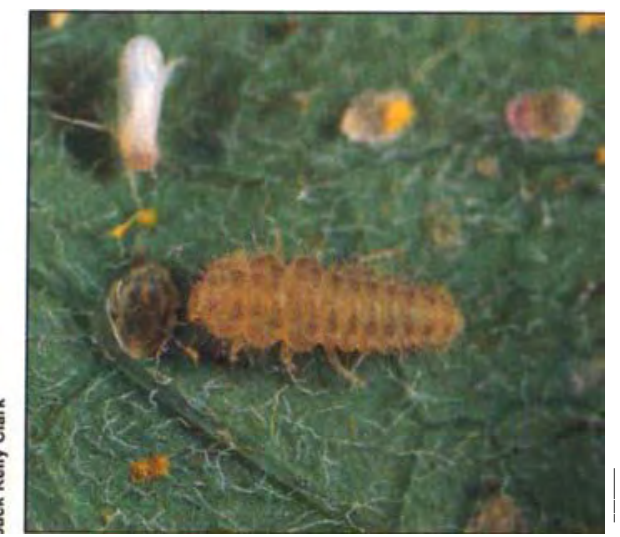

A third Instar immature D. pus/lus.

\title{
Predatory beetle may suppress silverleaf whitefly
}

\author{
Kevin M. Heinz a James R. Brazzle a Charles H. Pickett \\ Eric T. Natwick $\square$ Judy M. Nelson a Michael P. Parrella
}

\begin{abstract}
The coccinellid beetle, Delphastus pusillus, may be able to suppress the silverleaf (or strain $B$ sweetpotato) whitefly that has infested California agriculture. Life history characteristics of this predator indicate that it is most effective as a biological control agent at high whitefly densities. D. pusillus releases in Imperial Valley cotton trials reduced immature whitefly densities to one-third of the densities found in cotton plots receiving no releases.
\end{abstract}

Widespread infestation by the silverleaf (or strain B sweetpotato) whitefly, Bemisia tabaci (Gennadius), has caused economic damage unmatched in the history of agricultural entomology to crops in the southwestern United States and northern Mexico (California Agriculture, September-October 1992 and January-February 1993). B. tabaci serves as a vector for plant pathogenic viruses, induces squash silverleaf in cucurbits and irregular ripening in tomatoes, and produces honeydew, which leads to sticky cotton and the development of sooty molds. B. tabaci also drains nutrients from the plant as it feeds. The drain on plant nutrients by enormous $B$. tabaci populations feeding on crops from spring through early fall has caused much of the economic loss to southeastern California agriculture. In addition, over the past 4 years, B. tabaci has become the major whitefly species attacking California greenhouse crops.

Explanations for the recent outbreaks are speculative. However, one fact is certain: alternatives to current whitefly management practices must be developed if production is to be sustained in infested areas. Researchers have begun examining the many parasitoids and predators reported to successfully establish on $B$. tabaci throughout its geographic range. Because the distribution of $B$. tabaci encompasses a wide array of environmental conditions, host plants and agricultural practices, it is unlikely that a single species of parasitoid or predator will control it. Fortunately, many of $B$. tabaci's natural enemies endemic to the United States are reared in laboratories throughout the coun- try. Yet, with the possible exception of the commercially available wasp Encarsia formosa Gahan, their ability to suppress $B$. tabaci populations under a variety of conditions has not been determined. Here we report our findings on Delphastus pusillus (LeConte), one of the several natural enemies we are evaluating for use in $B$. tabaci biological control programs in field crops and greenhouse-grown poinsettias.

\section{Small, shiny beetle}

Adult $D$. pusillus are small, shiny black coccinellid beetles 1.3 to $1.4 \mathrm{~mm}$ in length; the larvae are pale yellowish white. This beetle, related to aphidfeeding ladybird beetles, has been reported as a predator of various whiteflies on citrus in Florida and Mexico and on cassava in Colombia, South America. D. pusillus is distributed widely across the central and southeastern United States, south through Central America and into South America as far as Peru. This geographic range suggests that $D$. pusillus should be able to survive and reproduce in the diverse California climate. $D$. pusillus is already found widely in the coastal and subcoastal areas, where it was introduced by Rose and DeBach from 1966 to 1977 (California Agriculture, July-August 1981). According to the results of laboratory studies conducted by University of Florida scientists, the egg-to-adultemergence development time for $D$. pusillus is 21 days at $28 \pm 3^{\circ} \mathrm{C}(82 \pm$ $\left.5.4^{\circ} \mathrm{F}\right)$. By comparison, the development time for $B$. tabaci on cotton at a constant $27.5^{\circ} \mathrm{C}\left(82^{\circ} \mathrm{F}\right)$ is approximately 18 days. Larval and adult beetles feed on all stages of $B$. tabaci, but the daily consumption of prey by adult beetles and the time required to consume prey are directly correlated to the size or development stage of the whitefly.

Various biological parameters relating to the efficacy of this predator (adult longevity, prey consumption and fecundity as a function of whitefly density) were measured on two poinsettia cultivars - 'Annette Hegg Brilliant Diamond' and 'Lilo'. Leaf hair, or trichome, density, which is often negatively correlated with the searching ef- 
ficiency of natural enemies, is onethird greater on 'Lilo' than on 'Annette Hegg Brilliant Diamond', hence the need to compare $D$. pusillus performance on the two cultivars. The interaction between $D$. pusillus and a parasitoid found in California and other areas, Encarsia pergandiella Howard, was measured on 'Lilo' only. During the studies, average daily temperatures were $27.0 \pm 1.5^{\circ} \mathrm{C},\left(81 \pm 3^{\circ} \mathrm{F}\right)$ and daily photoperiods were 16L:8D.

\section{Adult longevity}

Adult $D$. pusillus longevity was measured by placing a newly emerged adult in a petri dish containing a poinsettia leaf infested with either $B$. tabaci eggs or third instar nymphs. The dishes were checked daily for the presence of live adult beetles, and the leaves were changed every other day. Forty adults were evaluated per cultivar, and poinsettia cultivar-dependent differences in longevity were detected with a two-way analysis of variance and Tukey's means separation test (fig. 1). Adult longevity did not vary significantly between the two poinsettia cultivars, but significant differences between sex and prey item were detected. Female adults feeding on $B$. tabaci nymphs lived significantly longer than males or females feeding on $B$. tabaci eggs. No significant differences between males feeding on nymphs and females feeding on eggs

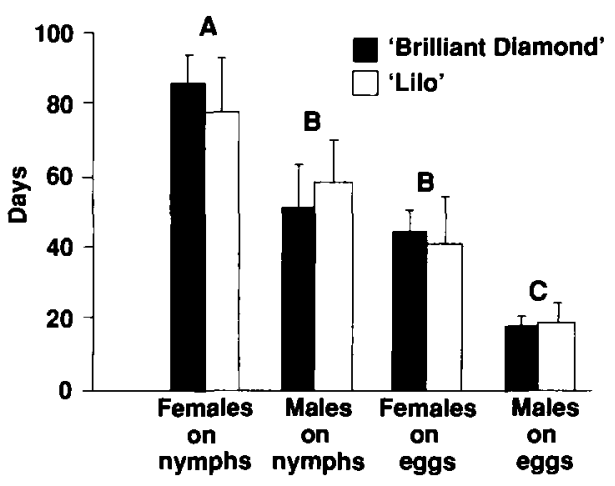

Fig. 1. Mean longevity of D. pusillus beetles preying on either $B$. tabaci eggs or third instar nymphs $\pm 1 \mathrm{SE}$. Vertical bars with the same letter are not statistically different at $p=0.05$ (1-way ANOVA with Tukey's means separation). Studies were conducted on two poinsettia cultivars; one cultivar, 'Annette Hegg Brilliant Diamond', has $33 \%$ fewer trichomes per unit area than the second cultivar, 'Lilo'. were detected, but both lived significantly longer than males feeding on eggs.

From these results, we conclude that host plants that differ only in trichome density will probably not influence the adult longevity of $D$. pusillus. Female and male adult beetles lived on average 64 and 36 days, respectively. These lifespans are 5 to 10 times longer than adult longevities typically reported for $B$. tabaci parasitoids.

\section{Prey consumption and egg laying}

We used the following procedure to study prey consumption and the number of eggs laid as functions of prey density. Individual $D$. pusillus beetle adults of unknown age were placed in a small cage containing a three-leaf poinsettia plant infested with third-instar $B$. tabaci nymphs or eggs (the number of which were determined by counting live and preyed-upon immatures at the end of the study). After a 3-day exposure period, the plants were removed and both the numbers of prey consumed and the number of $D$. pusillus eggs oviposited were counted with the aid of a dissecting microscope. Death of a whitefly due to $D$. pusillus predation can easily be distinguished from death by other causes. Only a flattened, empty whitefly cuticle is left after complete consumption, while in an incompletely consumed whitefly, disrupted internal organs are visible. This is compared to death by dissication or leaf senescence, which are characterized by darkening of the internal organs and gross deformation of the outer cuticle without any puncture marks.

The relationship between the density of available hosts and prey consumption was evaluated by leastsquares linear regression. For both prey types and for both cultivars, a significant positive linear relationship existed between the number of prey consumed and the number of prey available (fig. 2). Analysis of covariance was used to detect differences between prey types and between cultivars. The number of whitefly nymphs consumed by individual beetles over a 3-day period was significantly greater than the number of eggs consumed over the same period, regardless of the poinsettia cultivar $(\mathrm{F}=22.45, \mathrm{df}=$ 1,$155 ; \mathrm{p}=0.0001$ ). Prey consumption was also significantly greater on 'Annette Hegg Brilliant Diamond' (the cultivar with significantly fewer trichomes) than on 'Lilo', whether the beetles fed on whitefly eggs or nymphs $(\mathrm{F}=55.89, \mathrm{df}=1,155 ; \mathrm{p}=$ 0.001 ).

Results from these predation studies suggest that it may be easier for $D$. pusillus to locate whitefly nymphs than eggs, and therefore beetles will reduce whitefly nymph densities to a greater extent than they will reduce egg densities. Because a substantial amount of natural mortality occurs during the first instar or crawler stage of $B$. tabaci development, beetle predation on the later instars in the field should dramatically increase the overall level of whitefly mortality and hence increase the overall potential for controlling whiteflies. Furthermore, beetle predation will be greater on host plants with fewer trichomes, again increasing the chance of achieving successful control on these types of host plants.

The number of eggs oviposited by females was significantly and positively related to prey availability on 'Annette Hegg Brilliant Diamond', but no relationship existed between the number of ovipositions and prey densities on 'Lilo' (fig. 3). Again, analysis of covariance revealed differences between prey types and between cultivars. Egg laying by female beetles did

F, df, and p - briefly defined

The $F$ value is the test statistic from which the ANOVA significance value " $p$ " is derived. The degrees of freedom (df) are two numbers (a numerator and a denominator) which respectively reflect the number of treatments compared and the total sample size. When the first df value is equal to $1, \mathrm{~F}$ values greater than approximately 4 will be significant at the 0.05 level. For any given number of degrees of freedom, the higher the $\mathrm{F}$ value the greater the degree of significance. 
not differ significantly with the consumption of whitefly eggs or whitefly nymphs as prey items. However, egg laying was significantly greater on 'Annette Hegg Brilliant Diamond' than on 'Lilo', regardless of whether the beetles were feeding on eggs or nymphs $(\mathrm{F}=12.15, \mathrm{df}=1,79 ; \mathrm{p}=$ 0.0008 ). Although a definitive explanation is not possible at this time, the greater trichome density on 'Lilo' leaves may adversely affect the $D$. pusillus oviposition rate by reducing the number of prey the beetles can consume.

\section{Interactions with parasitoids}

Because the release of several natural enemy species may be necessary to suppress B. tabaci populations, and because we wish to reduce the probability of detrimental interspecific interactions, we examined the interactions between $D$. pusillus and other naturally occurring or released natural enemies. To examine the magnitude of one of these interactions, we provided D. pusillus a choice test of 'Lilo' poinsettia leaves infested with various stages of unparasitized and parasitized (by Encarsia pergandiella wasps) $B$. tabaci nymphs. If $D$. pusillus randomly forages on parasitized and unparasitized nymphs, parasitized nymphs should be preyed upon to the same extent as unparasitized nymphs, assuming equal handling times and encounter rates between parasitized and unparasitized nymphs. Therefore, in our experiments, the number of parasitized nymphs consumed by randomly foraging $D$. pusillus should be equal to the proportion of parasitized B. tabaci nymphs on a leaf multiplied by the total number of nymphs consumed by $D$. pusillus (figs. 4 and 5 , solid bars).

We placed individual fourth-instar D. pusillus larvae, which are also predaceous on immature whiteflies, on single leaves possessing parasitized nymphs containing $E$. pergandiella larvae (approximately 7 days after oviposition) or pupae (approximately 14 days after oviposition). Prepupal stages of E. pergandiella were characterized by translucent larvae pressed against the whitefly cuticle; the pupal stages were characterized by tan pupae that were retracted from the walls of the whitefly cuticle. The leaves were placed within individual petri dishes, and, after a 24-hour exposure period, the number of nymphs consumed was counted (fig. 4, white bar). We examined $20 \mathrm{D}$. pusillus larvae, and compared the observed numbers of each age and size class of nymphs eaten to the expected numbers.

The interaction between adult $D$. pusillus and developing E. pergandiella was examined in B. tabaci nymphs parasitized 1, 5, 9 or 13 days before exposure to beetles. The physical structure of immature $E$. pergandiella changes significantly with time. Oneand 5-day-old E. pergandiella larvae adhere (together with their hosts) to the cuticle of whitefly nymphs, while 9and 13-day-old pupae are retracted from the cuticular wall of their hosts. Fifteen unparasitized fourth-instar whitefly nymphs and 15 nymphs containing developing parasitoids were removed from infested plants and secured to an uninfested $18-\mathrm{cm}^{2}$ poinsettia leaf section with minute drops of honey. The leaf sections that contained whiteflies and only one age class of developing parasitoids were fixed to the bottoms of petri dish covers with melted wax. Adult beetles were singly placed on leaves, the covers replaced

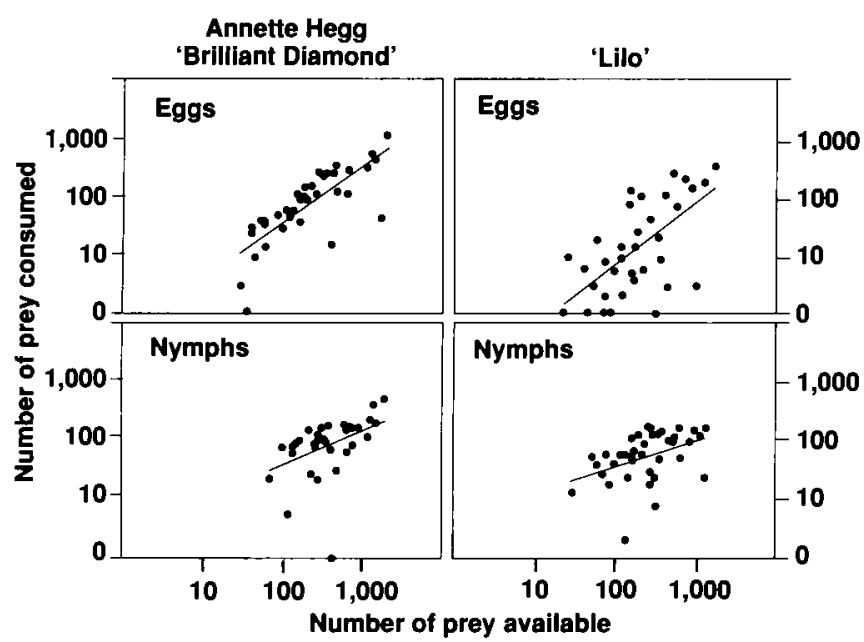

Fig. 2. Prey consumption by $D$. pusillus beetles foraging on three-leaf poinsettias for 3 days. Data are plotted on a logarithmic scale, and statistically significant (at $p=0.05$ ) least-squares linear regression lines are plotted for each cultivar and prey type. The equations describing these lines are:

For 'Annette Hegg Brilliant Diamond', $y=0.98 x-0.38, r^{2}=0.626$ (B. tabaci eggs as prey) and $y=0.91 x+0.06, r^{2}=0.287$ (B. tabaci nymphs as prey)

For 'Lilo', $y=1.08 x-1.28, r^{2}=0.373$ (B. tabaci eggs as prey) and $y=0.46 x+0.64, r^{2}=0.181$ (B. tabaci nymphs as prey)

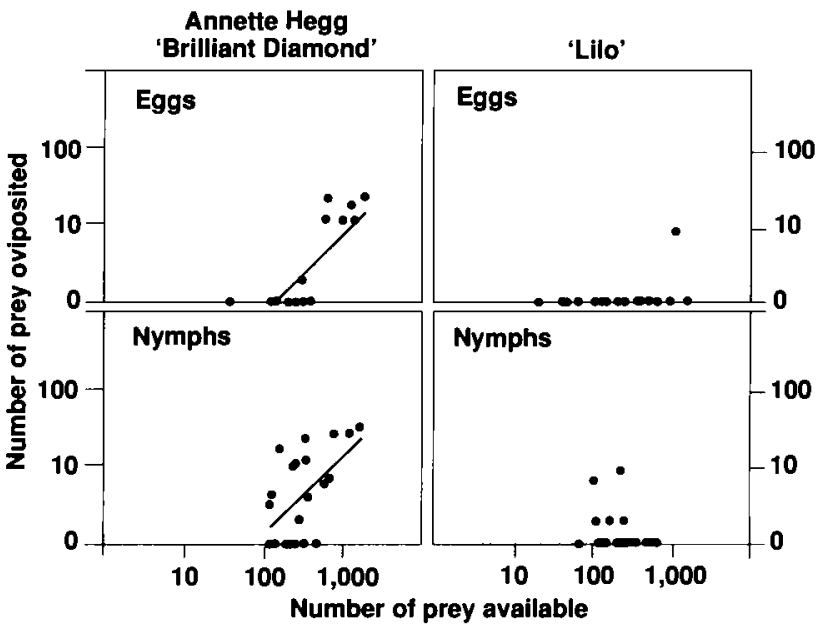

Fig. 3. Number of eggs oviposited by female beetles foraging on three-leaf poinsettia plants over 3 days. Data are plotted on a logarithmic scale, and statistically significant (at $p=0.05$ ) leastsquares linear regression lines are plotted for each cultivar and prey type. The equations describing these lines are:

For 'Annette Hegg Brilliant Diamond', $y=1.07 x-2.37, r^{2}=0.579$ (B. tabaci eggs as prey) and $y=1.01 x-1.93, r^{2}=0.306$ (B. tabaci nymphs as prey) 
and the dishes inverted. After a 24hour exposure time, the numbers of intact and preyed-upon parasitized and unparasitized nymphs were determined. A total of 24 beetles was assayed for each of the four parasitoid age classes, and the observed numbers of nymphs fed upon were compared to the expected numbers.

The observed frequencies deviated significantly from the expected, as determined by calculating G-statistics from a replicated goodness-of-fit test for both beetle larvae and adults. The advantage of this analysis is that the overall goodness-of-fit test can be partitioned into separate G-tests representing individual degrees of freedom between groups ( $G_{P}$ statistic) and within groups $\left(\mathrm{G}_{H}\right.$ statistic) in a manner analogous to that practiced in analysis of variance. It was therefore possible to detect differences in predation by adult beetles among parasitoid age groups.

Results from this test indicate that all beetle larvae behaved in a consistent manner $\left(\mathrm{G}_{\mathrm{H} \text { (Prepupae) }}\right.$ and $\mathrm{G}_{\mathrm{H} \text { (Pupae) }}$ statistics were not significant at $\mathrm{p}=$ 0.05 ), and that they tended to feed on parasitized nymphs significantly less than would be expected by random chance $\left(G_{P(\text { Prepupae })}=5.591, d f=1\right.$,

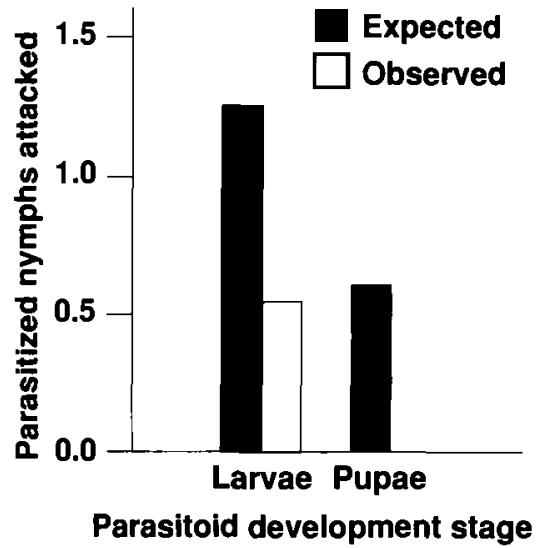

Fig. 4. Interaction of $D$. pusillus larvae with two development stages of $E$.

pergandlella. The expected values are the proportion of avallable parasitized nymphs multiplied by the total number of nymphs consumed (solid bars $\pm 1 S E$ ). The white bars ( \pm 1 SE) represent the observed number of nymphs preyed upon by immature beetles. Asterisks indicate treatments in which observed values are significantly different from expected values $(p=0.05)$. $\mathrm{p}<0.05 ;$ and $\mathrm{G}_{\mathrm{P}(\text { Pupae })}=16.497, \mathrm{df}=1$, $p<0.001$;) (fig. 5). The intensity of the interaction between adult $D$. pusillus and developing E. pergandiella depends on the wasp's development stage. The frequency of beetle predation on 1- and 5-day-old E. pergandiella was not significantly different from the expected frequency $\left(\mathrm{G}_{\mathrm{P}(\mathrm{day} 1)}\right.$ and $G_{P(\text { day 5) }}$ were not significant at $p=0.05$ ). By contrast, beetle predation on 9 - and 13-day-old E. pergandiella was significantly less than expected by random chance $\left(\mathrm{G}_{\mathrm{P}(\text { day 9) }}=16.391, \mathrm{df}=1\right.$, $\mathrm{p}<0.001$; and $\mathrm{G}_{\mathrm{P}(\text { day } 13)}=49.019$, $\mathrm{df}=1, \mathrm{p}<0.001$ ). Because the $\mathrm{G}_{\mathrm{H}}$ statistics were not significant at $p=0.05$, we conclude that the beetles behaved in a consistent manner within each of the four treatments.

Results from these experiments indicate that $D$. pusillus larvae and adults become more discriminating as the parasitoid develops. Larvae and adult predation on parasitoid larvae ( $\leq 7$ days old) indicate that parasitoid populations may be adversely affected by $D$. pusillus. However, whether this potential negative impact on parasitoid populations reduces the chance of achieving successful biological control cannot be determined until further data are collected.

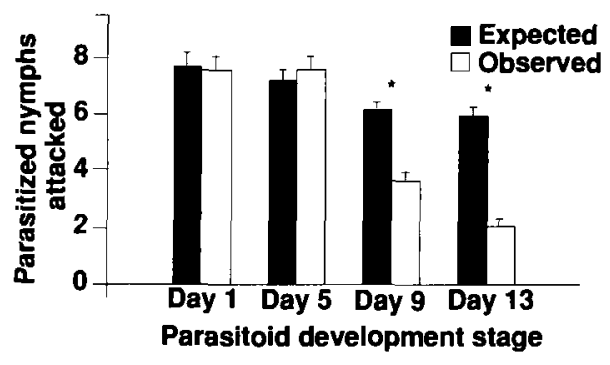

Fig. 5. Interaction of $D$. pusillus adults with four development stages of $E$. pergandiella. The expected values are the proportion of available parasitized nymphs multiplied by the total number of nymphs consumed (solid bars $\pm 1 \mathrm{SE}$ ). The white bars ( \pm 1 SE) represent the observed number of nymphs preyed upon by adult beetles. Asterisks indicate treatments in which observed values are significantly different from expected values $(p=0.05)$.
Laboratory studies like the ones reported here help to identify the potential strengths and shortcomings of a natural enemy's ability to suppress a whitefly population. Two other evaluations have also been conducted to quantify the potential of D.pusillus as a successful biological control agent for B. tabaci. The goal of the first evaluation - a greenhouse study examining the relative ability of three natural enemy species to suppress $B$. tabaci infesting poinsettias - was to eliminate poorly adapted species from consideration as potential biological control agents. The goal of the second evaluation - a field study conducted in Imperial Valley cotton - was to quantify the level of suppression provided by D. pusillus releases relative to experimental controls that were not receiving natural enemy releases.

\section{Greenhouse poinsettia trial}

Four large cages ( $4 \mathrm{ft}$ wide by $6 \mathrm{ft}$ long by $3 \mathrm{ft}$ high) covered with cotton organdy were erected in a greenhouse on the UC Davis campus. Twenty-four 1-month old 'Lilo' poinsettia plants transplanted into 6-inch-diameter pots were placed in each cage. Interplant spacing was $1 \mathrm{ft}$, a distance similar to that used by commercial poinsettia growers. In the 3 weeks immediately after the plants were positioned within the cages, 24 adult whiteflies were released into the cages each week to start a $B$. tabaci infestation. After the third whitefly release, weekly releases of natural enemies were initiated at a rate of 3 individuals per plant per week. Releases continued over the 12week duration of the study. One cage receiving no natural enemy releases acted as an experimental control, and one each of the three remaining cages received releases of $D$. pusillus and the parasitoids Encarsia luteola Howard and Encarsia pergandiella. Each week, one leaf was sampled at random from each plant within a cage, and the number of live whiteflies was recorded by development stage for each leaf. Between-treatment differences were detected using Wilcoxon's signed-ranks test for two groups, arranged as paired observations. In this test, the data are treated as randomized blocks, with 
sample dates as blocks and the species differences as the fixed treatments to be tested.

Results of the trial are shown in figure 6. Data for the no-release treatment are plotted for only the first 9 weeks of the study. Starting in week 9, plants in the control cage began to drop their lower leaves (which contained whitefly pupae) and die, probably because of severe whitefly infestations. Over these first 9 weeks, the whitefly densities in each cage receiving natural enemy releases were significantly lower than the density observed in the cage not receiving any natural enemy releases. By week 9 , releases of $D$. pusillus qualitatively provided the best control by suppressing whitefly populations by almost 2 orders of magnitude relative to the control. However, the average whitefly density (over all sample dates) was not significantly different from the average whitefly density observed in the $E$. luteola or E. pergandiella release cages. The lack of statistical significance is probably due to the low number of replications within the trial. While the trial is currently being replicated, the results presented here should serve as hypotheses for further study.

\section{Imperial Valley cotton trial}

Eight $1 / 2$-acre plots of cotton (var. DPL5461) were planted at the UC Desert Research and Extension Center in El Centro, California, on May 5, 1992. The plots were established in line with commercial practices, except that no pesticides were applied during the crop cycle. The efficacy of $D$. pusillus releases was to be examined under conditions in which $B$. tabaci and natural enemy movements were present or absent. To prevent mass movements of $B$. tabaci, whitefly exclusion cages were constructed of schedule 40 PVC pipe frames (6.67 ft wide by $10 \mathrm{ft}$ long by $6 \mathrm{ft}$ high) covered with 42-mesh Lumite screening material. On July 14, one cage, covering approximately 40 cotton plants, was arbitrarily placed into each of the eight cotton plots.

A 27-feet-wide border of cotton plants was established around the outer perimeter of each plot to elimi- nate edge effects. A stratified random sample from the remaining $1 / 4$ acre of each plot was collected weekly beginning on July 14. Each plot was subdivided into 30 subplots, and a vertically stratified leaf sample was collected from a plant randomly selected from each subplot. The vertically stratified sample consisted of mainstem leaves removed every 4 inches along the central stem of each cotton plant. Four plants from each of the eight cages were sampled in a similar fashion. The number of live, dead and parasitized immature whiteflies was determined for a $1.5-\mathrm{cm}^{2}$ leaf punch taken from the center of each leaf sample.

On July 4, plant stands in each plot were counted and plots were paired according to plant density. Within each pair, one plot was designated for $D$. pusillus releases and the other plot was designated a control plot. Cages received the same designation (release or no release) as the surrounding plot. From July 21 through September 1 (open fields) and September 17 (cages), four cotton plots and four cages received weekly releases of $D$. pusillus. Equal numbers of beetles per plant were released each week; in total, 35,144 adult beetles were released into the four cages and open-field plots during the study. All beetle releases were carried out before 9 a.m.

The last of the open-field plot samples was taken on August 26 in order to remain in compliance with Imperial County regulations for boll termination no later than September 1. Because the cages were excluded from these regulations, leaf samples were collected from the cages through October 14 .

The effects of the $D$. pusillus releases were evaluated by using a repeated measures analysis of variance to compare the whitefly densities in the release areas with those in the non-release areas. Data were transformed using a polynomial tranformation prior to analysis. No significant between-treatment differences could be detected in the open-field conditions. However, it is noteworthy that over the last three sample dates whitefly densities in fields receiving $D$. pusillus releases were declining relative to den- sities in fields not receiving the beetle releases. In the cages (fig. 7), significant between-treatment differences in the whitefly densities were detected ( $F=13.99, \mathrm{df}=1, \mathrm{p}=0.0096)$. Because the magnitude of this difference increased dramatically between September 9 and October 14, a significant sample DATE $\times$ TREATMENT effect was also detected ( $\mathrm{F}=5.35, \mathrm{df}=13$, $p=0.0111$ ). If sampling could have been continued, it is possible that similar results would have been observed in the open fields.

Parasitoids in the genera Encarsia and Eretmocersus, also found to be parasitizing whitefly nymphs, were not adversely affected by $D$. pusillus releases. That is, parasitoid densities were not significantly reduced (F-statistics calculated from repeated mea-

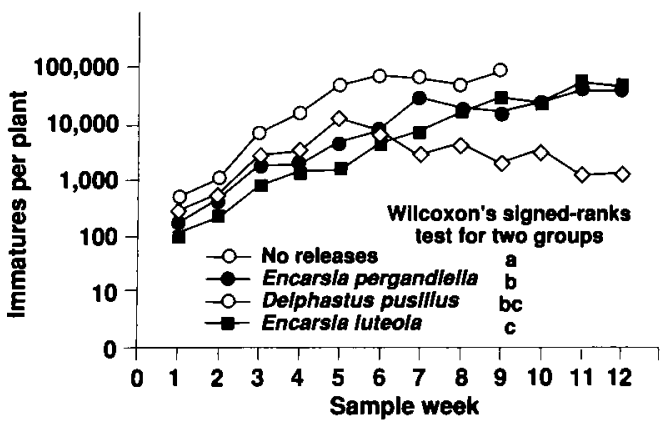

Fig. 6. Comparison of B. tabaci densities in poinsettia cages receiving releases of three different species of natural enemies. Sample weeks (weeks receiving natural enemy releases) are depicted along the $x$ axis. The $y$-axis represents the number of immature whiteflies per plant $(=$ the number of whiteflies per leaf multiplied by the number of leaves per plant) on a logarithmic scale.

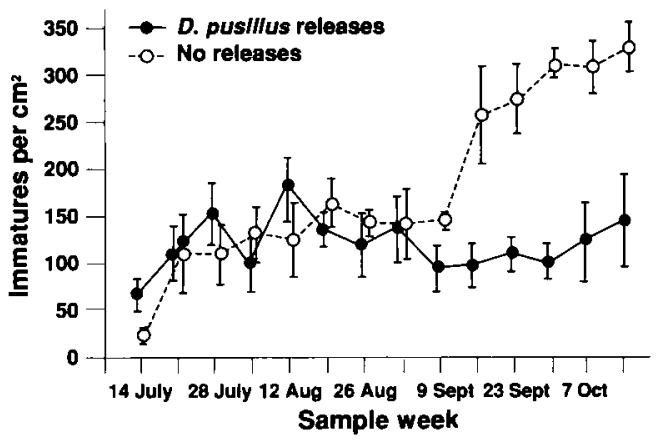

Fig. 7. B. tabaci densities in cotton enclosure cages. The sample dates are depicted along the $x$-axis, and the $y$-axis represents the number of immature whiteflies per $\mathrm{cm}^{2}$ of leaf area. Whitefly densities are expressed as the mean ( $N=4$ replicates) \pm 1 standard error (vertical bars). 


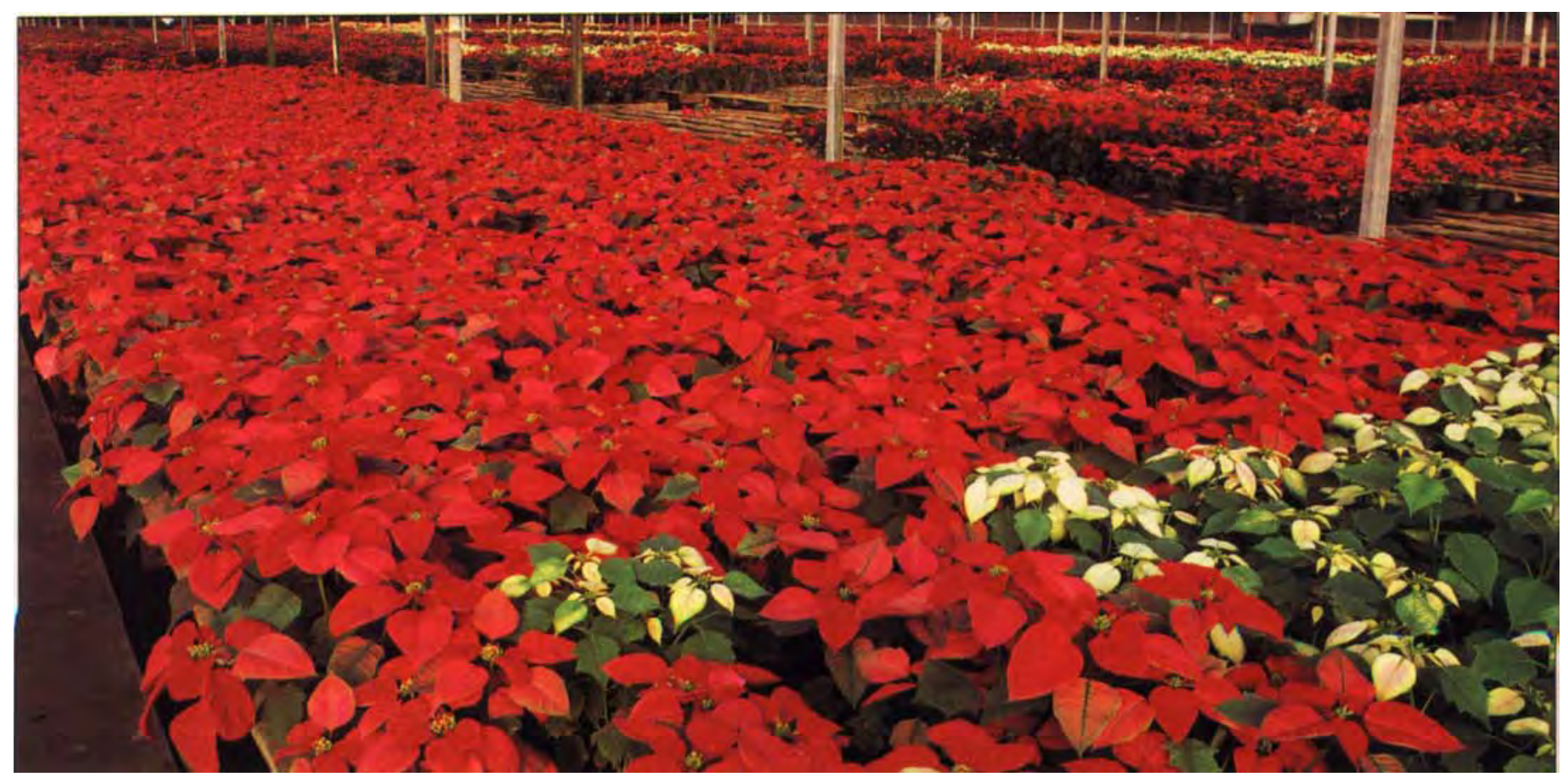

sures analysis-of-variance in cotton plots receiving $D$. pusillus releases compared to plots not receiving the releases. These data suggest that $D$. pusillus can be released with no apparent adverse effects on existing parasitoid fauna, or that the beetles may be used as one component of a multiplespecies release.

Our results suggest that releases of $D$. pusillus may suppress $B$. tabaci populations. Introductions of this predatory beetle may provide a partial solution to the devastating $B$. tabaci problem in Imperial County. $D$. pusillus may also be useful in managing patchy whitefly outbreaks in greenhouses containing ornamental crops that cannot tolerate even moderate whitefly densities. The study results further indicate that additional, large-scale greenhouse and field evaluations of $D$. pusillus releases should be conducted to define with greater precision the role of this predator within an overall management program for $B$. tabaci. A cooperative project between UC Davis, the Biological Control Program of the California Department of Food and Agriculture, and the UC Desert Research and Extension Center has been initiated to conduct such evaluations.

K. M. Heinz is Assistant Research Scientist, J. R. Brazzle is a master's student, J. $M$. Nelson is a doctoral student and M. P. Parrella is Professor and Chair, all within the Department of Entomology, University of California, Davis; C. H. Pickett is Environmental Research Scientist with the Biological Control Program of the California Department of Food and Agriculture (CDFA), Sacramento, and E. T.
Prey consumption was significantly greater on poinsettias that have fewer trichomes, whether the beetles fed on whitefly eggs or nymphs.

Natwick is Imperial County Entomology Farm Advisor, UC Cooperative Extension, Holtville, California.

The Delphastus pusillus were originally supplied to UC Davis by the University of Florida and USDA/ARS in Apopka, Florida. Kathleen Casanave, Biological Control Program, CDFA, reared the $\mathrm{D}$. pusillus for field release into the Imperial Valley. Dr. Andrew Polaszek from the Institute of Entomology, London, performed parasitoid identification. Financial support for this work was provided by the American Floral Endowment; the California Association of Nurserymen; the California Department of Food and Agriculture, Biological Control Unit; and UCIPM. Poinsettia plants were provided by Paul Ecke Poinsettias, Encinitas, California.

\section{CALIFORNIA AGRICULTURE ASSOCIATE EDITORS}

Animal, Avian, Aquaculture and Veterinary Sciences

Richard H. McCapes

(2nd assoc. editor to be announced)

\section{Economics and Public Policy}

Harold O. Carter

Alvin Sokolow

\section{Food and Nutrition}

Barbara Schneeman

Eunice Williamson

Human and Community Development

Linda M. Manton

Karen P. Varcoe
Land, Air \& Water Sciences

J. Brian Mudd

Garrison Sposito

Henry J. Vaux, Jr.

\section{Natural Resources}

Daniel W. Anderson

John Helms

Richard B. Standiford

\section{Pest Management}

Michael Rust

Frank Zalom

Plant Sciences

Calvin O. Qualsat

G. Steven Sibbett

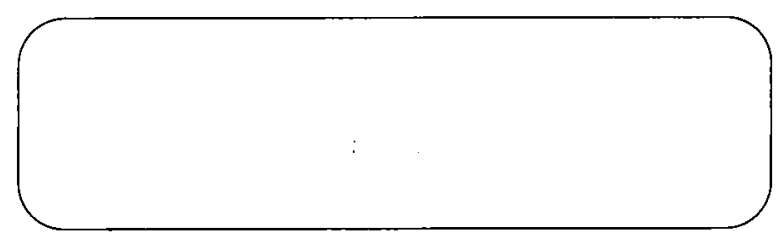

